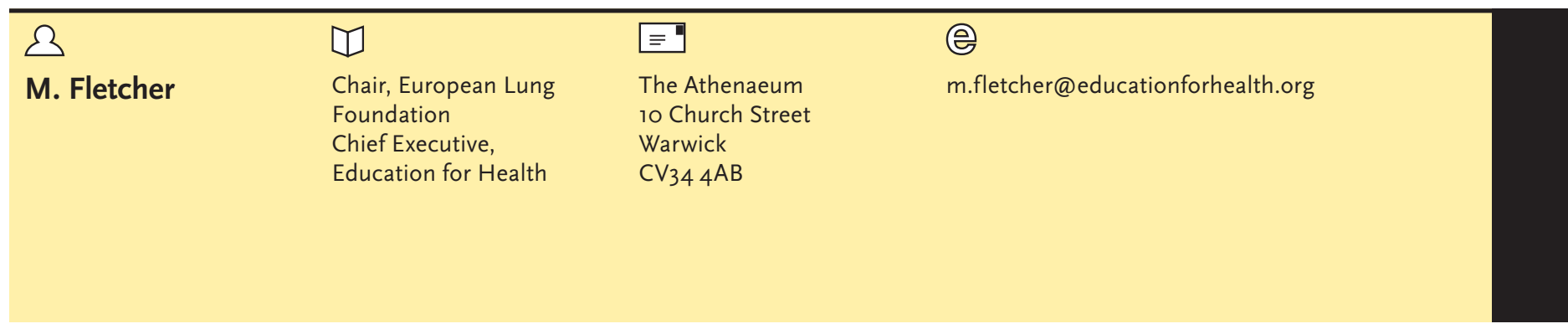

\title{
Bringing the patient voice to the ERS Annual Congress
}

It gives me great pleasure that I can write this editorial for Breathe to explain some fantastic progress made this year by the European Lung Foundation (ELF) and its growing family of patient organisations at the European Respiratory Society (ERS) Annual Congress.

However, the first question I may need to answer for the readers of Breathe is - why? Why invite patient organisations to take part in the Congress, when its primary focus and goal is surely to meet the needs of $>20,000$ respiratory professionals who come to share the latest research and clinical developments with their colleagues?

The first answer is: the Congress is all because of and for the patient. Any developments in science and clinical care in respiratory medicine are to improve the quality of life of those living with respiratory disease. Therefore, engaging patients and their organisations in the Congress allows them to hear about and report back to their communities the work being done by ERS members and Congress attendees. This is of course aided by the ELF, which reports daily to the media about key abstracts and hot findings during the Congress, and also has a regular presence on social media explaining to the public what new findings might mean to them and their families.

Secondly, as was exemplified in the ELF symposium held during the Congress, public and patient input into research and guidelines has been shown to help identify issues that may be overlooked by healthcare professionals, highlight areas where the patient's perspective differs from health professionals', and ensure that guidelines address key issues of concern to patients [1]. It can be a win-win situation for professionals and patients alike, and we need to find new ways to optimise these interactions to benefit all concerned.

Finally, as demonstrated fantastically by the recently published European Respiratory Roadmap [2], the European respiratory community needs to speak with one voice. Healthcare professionals, patients and the public need to work together in concert to ensure key advocacy messages are heard nationally and at the European level. Only by harnessing together the personal experience of the patient and the knowledge of the professional will true progress be made.

I would like to thank the ERS and its members for having the foresight and faith to drive forward patient engagement in their work and particularly their Congress and we look forward to further developments in the coming years.

\section{Showcasing the work of patient organisations across Europe}

A total of 16 patient organisations joined the ELF and national societies this year at the Congress in the World Village. This was an opportunity for patient organisations to exhibit their work and display materials that could benefit healthcare
Statement of interest None declared. 
professionals in their interaction with patients. The layout of the patient organisation section of the village encouraged networking and interaction between the groups to develop effective and longlasting partnerships. All the patient organisations participated for the first time in an ELF advisory committee meeting, in order to provide the ELF with the vital advice and support it needs to ensure patients are integrated in the ERS to the best possible effect and to ensure that their voice is heard alongside that of the professionals.

\section{Bringing together professionals and patients}

One of the aims of the ELF this year has been to integrate patient organisations with you, the professionals - to find opportunities for both to interact in a meaningful and productive manner. At the Congress, this was achieved via two symposia, both of which focused on public and patient input in science and research.

The clear message was that there is still a long way to go until patients are integrated into all aspects of science in the most effective way and that it can be difficult for health professionals to know how to facilitate this. The ELF hopes that it can aid this by providing training for patients who wish to take part in research projects and to educate professionals in best practice. Further symposia and sessions will be held in 2012 and this year's presentations can be accessed at www.europeanlung-foundation.org/congress2012.

\section{Rewarding excellence in patient care}

The ELF Award is given annually to someone who has made a big impact on public health in the respiratory field. Past recipients include: Michael Bloomberg, Mayor of New York, to mark his outstanding contributions to combat tobacco use worldwide; Albert Osterhaus, one of the world's leading virologists, in recognition of his groundbreaking research into the viruses responsible for avian flu and severe acute respiratory syndrome (SARS); and a collective group of 35 Members of the European Parliament for their commitment to the fight for a tobacco-free Europe

This year the ELF was delighted to acknowledge Professor Elizabeth Juniper for her work to promote health-related quality of life in asthma care and clinical research. The ELF felt that the development of health-related quality of life tools in asthma clinical practice has helped clinicians to quickly and accurately identify problems and limitations that are important to patients. Also, it has allowed patients to learn about the features of asthma that are important for good control, facilitating shared decision making and increased compliance. The ELF has created a factsheet to help you explain these concepts to patients. It is available in this edition of Breathe or at www.european-lung-foundation.org/ factsheets.

\section{Launching World Spirometry Day 2012}

I hope all ofyou who attended the ERS Congress noted the many signs that were displayed around the congress centre to announce World Spirometry Day (WSD) 2012. The ERS Congress saw beginning of a year-long effort to build on the success of WSD 2010 and to get people to join the race for healthy lungs in the Olympic year - 2012.

The opening ceremony saw the passing of the spirometry "baton" from ERS President Klaus Rabe to the American College of Chest Physician President David Gutterman. This symbolised the commitment of the respiratory societies from across the globe who form the Forum of International Respiratory Societies (ACCP, ALAT, APSR, ACCP, ERS, PATS and the Union) to support and engage their members in this campaign.

The ELF is proud to be organising WSD in 2012 in partnership with FIRS and we hope that we can call on you all to play a part in making this a massive awareness effort for lung health. For more information, please contact the ELF on info@europeanlung.org or go to the website www.WSD2O12.european-lung-foundation.org.
References

1. Wedzicha W, Fletcher M, Powell P. Making ERS guidelines relevant and accessible: involving patients and the public. Breathe 2010; 8: 9-11.

\footnotetext{
2. European Respiratory Roadmap. Lausanne, European Respiratory Society, 2011. Available from www.ersroadmap.org
} 